\title{
Clinical and Angiographic Characteristics of Female Patients Undergoing Coronary Angiography in a Tertiary Hospital in Bangladesh
}

\author{
Sahela Nasrin', F. Aaysha Cader ${ }^{2}$, M. Maksumul Haq ${ }^{3}$
}

\begin{abstract}
Background \& objective: Coronary artery disease (CAD) is increasingly prevalent among female population, particularly in South Asia, and a large number of female patients currently undergo coronary angiography for a variety of indications. The objective of this study was to investigate the clinical and angiographic characteristics of female patients undergoing coronary angiogram, in a tertiary cardiac center in Bangladesh.

Methods: This retrospective observational study was conducted at Ibrahim Cardiac Hospital \& Research Institute, Dhaka, Bangladesh during the period from $1^{\text {st }}$ September 2005 to $31^{\text {st }}$ August 2016. A total of 7,627 female patients who underwent coronary angiography were included. Obstructive coronary artery disease (CAD) was defined as a stenosis $\geq 70 \%$ in at least one of the three major coronary arteries or a stenosis $\geq 50 \%$ in left main stem.

Result: Nearly two-thirds (64.4\%) of patients comprised of age group of 41-60 years with mean age of the patients being $55.4 \pm 10.2$ years. Unstable angina $(38.2 \%)$ was the commonest indication for coronary angiography followed by stable ischemic heart disease $(25.1 \%)$, non-ST segment elevation myocardial infarction $(12.8 \%)$, ST segment elevation myocardial infarction $(9.3 \%)$, left ventricular failure (7.5\%), post-myocardial infarction angina (6\%) and atypical chest pain (1.3\%). Over three quarters were hypertensive $68.3 \%$ were diabetic and $29 \%$ and dyslipidemiac. Over $40 \%$ of the patients were overweight and $20 \%$ were obese. On trans-thoracic echocardiography, $65.2 \%$ had normal left ventricular (LV) systolic function; $17.6 \%$ and $9.9 \%$ had mild and moderate LV systolic dysfunction respectively. Nearly 30\% had normal epicardial coronary arteries on angiography, while $17.4 \%, 16.5 \%$ and $37.2 \%$ had triple vessel disease (TVD), double vessel disease (DVD) and single vessel disease (SVD) respectively. Following angiography, 33.4\% were advised PCI, 30.2\% optimal medical management and 15.3\% CABG. A few (3.2\%) were advised for revascularization either by CABG or PCI.

Conclusion: Unstable angina is the most common indication for coronary angiography among Bangladeshi females. A clustering of risk factors for CAD such as hypertension, diabetes and overweight or obesity are observed in them. Of the obstructive CADs, SVD is the most frequent finding, indicating that females undergoing CAG are likely to have diffuse CAD, although left main disease is not uncommon in this population. Further comparative studies with matched male population are recommended to find the differences in clinical and angiographic findings with respect to sex.
\end{abstract}

Key words: Coronary artery disease, Women etc.

\section{Authors' information:}

${ }^{1}$ Dr. Sahela Nasrin, MBBS, MCPS (Med), MD (Card), Consultant \& Associate Professor, Ibrahim Cardiac Hospital \& Research Institute (ICHRI), Dhaka.

${ }^{2}$ Dr. F. Aaysha Cader, MBBS, MRCP (UK), Registrar \& Specialist in Cardiology, Ibrahim Cardiac Hospital \& Research Institute (ICHRI), Dhaka.

${ }^{3}$ Prof. M. Maksumul Haq, MBBS, FCPS, FRCP, FACP, Professor \& Head, Department of Cardiology, Ibrahim Cardiac Hospital \& Research Institute (ICHRI), Dhaka.

Correspondence: Dr. Sahela Nasrin, Phone: +8801766089094 E-mail:nasrin_jhumur@hotmail.com 


\section{INTRODUCTION}

Cardiovascular disease (CVD) is the leading cause of mortality among women ${ }^{1}$ and contributes $38 \%$ of cardiovascular death globally. ${ }^{2}$ The lifetime risk of a woman dying from heart disease is more than eight times higher than from breast cancer. ${ }^{3}$ But unfortunately their cardiovascular diseases still remain largely ignored. ${ }^{4}$ The importance \& severity of coronary artery disease (CAD) are underestimated in women. ${ }^{5}$ CAD is not a rare entity in women, however the process is delayed by approximately 10-20 years in comparison to men. ${ }^{6,7}$ The mortality \& morbidity associated with CAD is significantly on the rise among women of Asian countries as supported by data from India and China. ${ }^{8-13}$

During post-menopausal years there is an increased overall risk of CAD in women. Arterial hypertension is detected more often at age 65 years and older and increases with age. The most widespread form is isolated systolic hypertension. ${ }^{8}$ Lipid profile alteration like low HDL and high triglycerides is a frequent cause of CAD in women than high concentration of LDL alone. ${ }^{14}$ Lori and associates showed women presented more frequently with unstable angina than NSTEMI; STEMI and sudden cardiac death, that are more common presentations in men. ${ }^{9}$ Multiple studies have shown that women with acute coronary syndromes (ACS) are less likely to be treated with guideline-directed medical therapies, ${ }^{15-19}$ less likely to undergo cardiac catheterization, ${ }^{15-20}$ and less likely to receive timely reperfusion. ${ }^{16,19,21-24}$

The basic cause of acute myocardial infarction (AMI) in both sexes is the obstructive atherosclerotic disease of the epicardial coronary arteries, but the plaque characteristics differ between sexes. Recent data suggest a greater role of microvascular disease in the pathophysiology of coronary events among women. ${ }^{25}$ The present study is, therefore, intended to describe the clinical and angiographic characteristics of female patients who underwent CAG for different indications.

\section{METHODS:}

\section{Study population:}

This retrospective observational study was conducted at Ibrahim Cardiac Hospital \& Research Institute, Dhaka, Bangladesh during the period from $1^{\text {st }}$ September 2005 to $31^{\text {st }}$ August 2016. All female patients who underwent coronary angiography during the period were included. They were identified from our dedicated Cathlab database. The study was conducted with the permission of Hospital Ethical Review Committee. Prior consent had been taken from the patients' near relatives before the procedure. The study was done compling with the Declaration of Helsinki for research involving human subject, 2013.

\section{Echocardiographic evaluation of left ventricular systolic function:}

Left ventricular (LV) systolic function was considered normal, when left ventricular ejection fraction (LVEF) was $\geq 55 \%$. Mild LV systolic dysfunction was considered when LVEF was $45-54 \%$, moderate LV systolic dysfunction was considered when LVEF was $30-44 \%$ \& severe LV dysfunction was considered, when LVEF was $<30 \%$.

\section{Image Acquisition \& interpretation:}

Coronary angiography was done by right femoral or radial route at operators discretion. Routine pre-medication was given comprising of oral sedative, antihistamine and steroid injection in those with prior history of allergy. Iodinated contrast media was used. If the patient had chronic kidney disease (CKD), iso-osmolar non-ionic media (Visipaque) was used. Image interpretation was performed by two independent readers. Disagreement between readers was solved by Heart Team discussion. Coronary arteries were segmented according to a modified version of the American Heart Association 15 -segment model (which includes the ramus intermedius, if present, as segment 16). Each coronary segment was visually analyzed with regard to the presence of stenosis and its severity as follows: no lesion, eccentric plaque $(<30 \%$ diameter), mild lesion (30-49\% stenosis), 
moderate lesion (50-69\% diameter stenosis), severe stenosis (70-98\% of diameter), subtotal stenosis (99\%), or total occlusion (100\%). Obstructive coronary artery disease (CAD) was defined as stenosis $\geq 70 \%$ in at least one of the three major coronary arteries (LAD, RCA and LCX) and/or stenosis $\geq 50 \%$ in left main stem.

\section{RESULTS:}

Nearly two-thirds $(64.4 \%)$ of patients comprised of age group of 41-60 years with mean age of the patients being $55.4 \pm 10.2$ years (Table I). Unstable angina (38.2\%) was the commonest indication for coronary angiography followed by stable ischemic heart disease $(25.1 \%)$, non-ST segment elevation myocardial infarction (12.8\%), ST segment elevation myocardial infarction $(9.3 \%)$, left ventricular failure $(7.5 \%)$, post-myocardial infarction angina (6\%) and atypical chest pain (1.3\%) (Fig. 2). Over three-quarters $(77.3 \%)$ were hypertensive and two-thirds $(68.3 \%)$ were diabetic and $29 \%$ dyslipidaemic (Fig. 3). Over $40 \%$ of the patients were overweight and $20 \%$ were obese (Fig. 4). On trans-thoracic echocardiography, $65.2 \%$ had normal left ventricular systolic function; $17.6 \%$ and $9.9 \%$ had mild and moderate LV systolic dysfunction respectively (Fig. 5). Approximately $30 \%$ had angiographically normal coronary arteries, while $17.4 \%, 16.5 \%$ and $37.2 \%$ had triple vessel disease (TVD), double vessel disease (DVD) and single vessel disease (SVD) respectively (Fig.6). Following angiography, 33.4\% were advised PCI, $30.2 \%$ optimal medical management and $15.3 \%$ CABG. A few (3.2\%) were, however, advised for revascularization either by CABG or PCI (Fig: 7).

\begin{tabular}{|lcc|}
\hline \multicolumn{3}{|l}{ TABLE I : Distribution of patients by their age } \\
\hline Age (Years) & Frequency & Percentage \\
$21-40$ & 572 & 7.5 \\
$41-60$ & 4912 & 64.4 \\
$>60$ & 2143 & 28.1
\end{tabular}

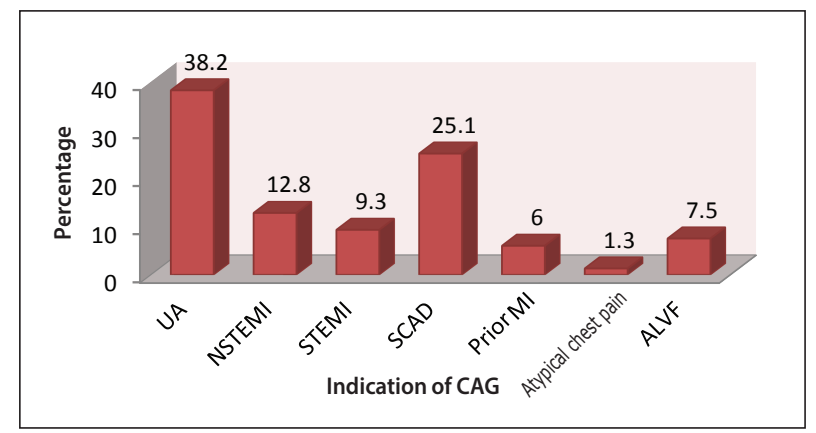

Fig: 2. Distribution of patients by Indications of CAG

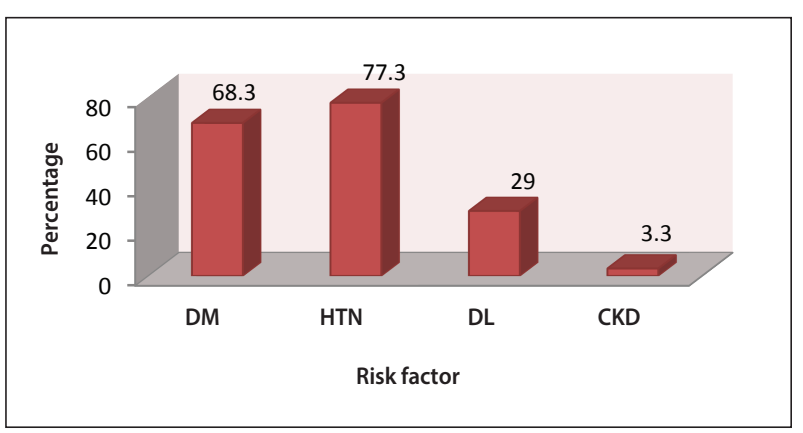

Fig: 3. Risk factors distribution in female patients

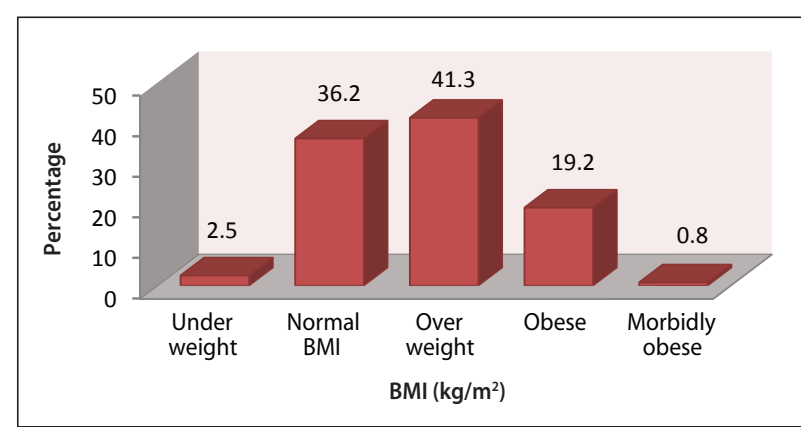

Fig: 4. Distribution of patients by their BMI

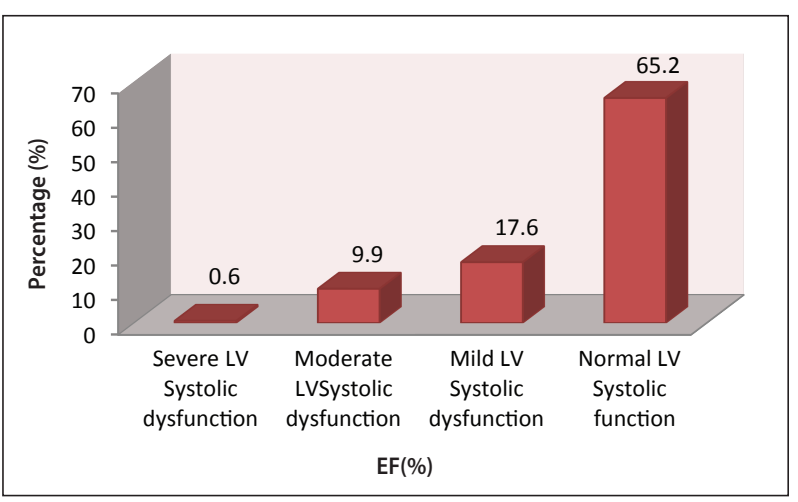

Fig: 5. Distribution of EF in the sudy subjects 


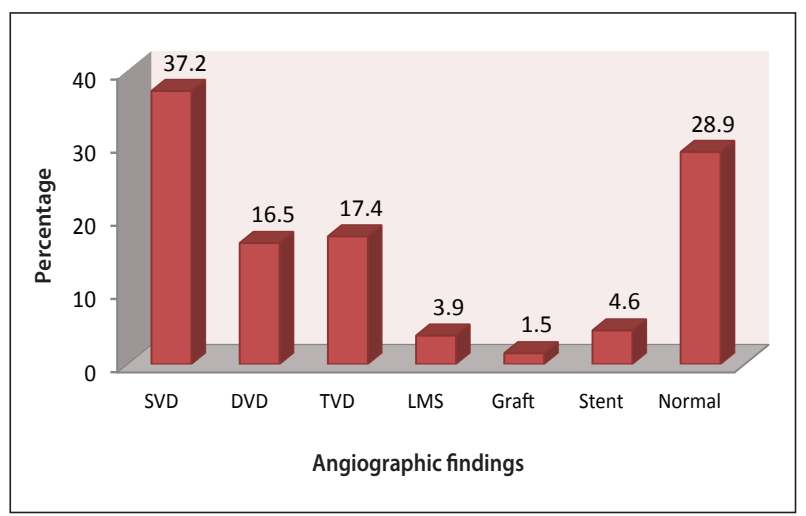

Fig: 6. Distribution of patients by angiographic findings

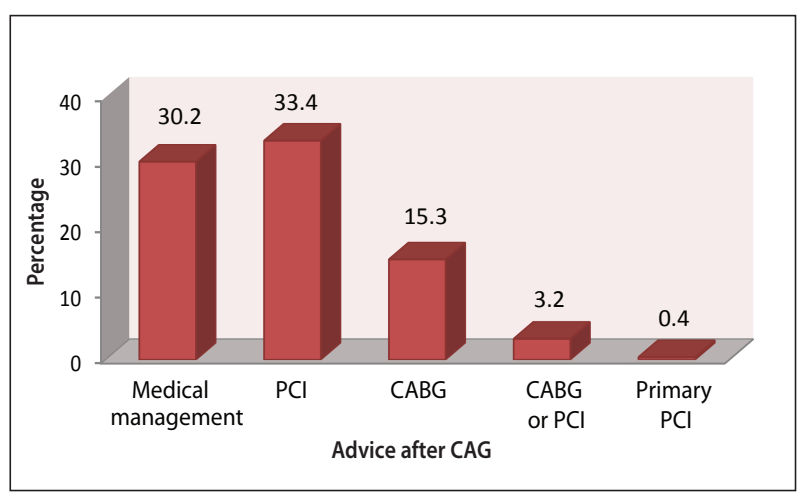

Fig: 7. Recommendation for management after CAG

\section{DISCUSSION:}

This retrospective study sheds light on a number of aspects of female CAD. The study demonstrated that approximately $65 \%$ of the patients were in their $4^{\text {th }}$ and $5^{\text {th }}$ decades of life. ${ }^{26}$ The National Health and Nutrition Examination Surveys (NHANES) of USA has shown that over the past several decades the prevalence of myocardial infarctions has increased in middle-aged ( 35 to 54 years) women, while declining in the same age-cohort of men. ${ }^{27}$ Lori and associates (2014) showed that women's presentation of CAD was different from that of men. Women usually present more with unstable angina than NSTEMI, STEMI and sudden cardiac death, which are more common presentations in men. ${ }^{9}$ Consistent with this finding, $38.2 \%$ of our population presented with UA, while only $12.8 \%$ and $9.3 \%$ of population presented with NSTEMI \& STEMI. Data from India and China also support this observation. ${ }^{8-13}$
Women have similar magnitude of atherosclerosis like that of men, but it looks and functions differently possibly due to estrogen or genetical reasons. ${ }^{28}$ Furthermore, females' plaque characteristics are known to differ in comparison to males. These different mechanisms in women result in different clinical presentations of CAD in women. In the present study over three-quarters $(77.3 \%)$ of our sampled population were hypertensive, $68.3 \%$ were diabetic and $29 \%$ dyslipidaemic and over $60 \%$ were overweight or obese. Consistent with these findings Manson, et $\mathrm{al}^{14}$ showed that women had a clustering of multiple risk factors for $C A D$, which matches well with our study findings. A large-scale study ( $\mathrm{n}=$ 16,736 ) on patients of acute coronary syndrome (registered between 1991 to the end of 2010) from Hamad Medical Corporation (HMC) in Qatar also demonstrated high prevalence rates of DM $(65.7 \%)$ and hypertension (68.1\%). ${ }^{29}$

Multiple studies have shown that women with acute coronary syndromes (ACS) are less likely to be treated with guideline-directed medical therapies,,$^{15-19}$ to undergo cardiac catheterization, ${ }^{15-20}$ $\&$ to receive timely reperfusion. ${ }^{16,19,21-24}$ This is also true for our female population, where only $0.4 \%$ of our total female patients underwent Primary PCI, although the STEMI population was nearly $10 \%$. In female population, endothelial dysfunction, small vessel- size and diffuse atherosclerosis are usually the causes of ischemia, rather than obstruction in the coronary arteries. ${ }^{30}$ Recent data also suggest a greater role of microvascular disease \& endothelial dysfunction in the pathophysiology of coronary events among women. ${ }^{25}$ These findings concur with our study wherein $29 \%$ of females were found to have normal epicardial coronary arteries, although they presented with signs and symptoms ischemic heart disease. Further comparative studies with matched male population are needed to validate these findings. Intravascular ultrasound (IVUS) or Optical coherence tomography (OCT)- directed identification of plaque morphology may shed further light into the aetiopathogenesis of CAD among females. 


\section{CONCLUSION:}

Unstable angina is the most common indication for coronary angiography among Bangladeshi females. A clustering of risk factors for CAD such as hypertension, diabetes and obesity are observed among them. In terms of obstructive $C A D, S V D$ is the most frequent finding, indicating that females undergoing CAG has less diffuse coronary artery disease, although left main disease is not uncommon. So careful advice should be given regarding life-style modification, diet and antihypertensive medication to reduce these events. Further comparative studies with matched male population are suggested.

\section{REFERENCES:}

1. Gholizadeh L, Davidson P. More similarities than differences: an international comparison of CVD mortality and risk factors in women. Health Care Women Int 2008;29:3-22. doi:10.1080/07399330701723756.

2. Mendis S, Puska P, and Norrving, B, eds., 2011. Global Atlas on Cardiovascular Disease Prevention \&Control[e-book]. Geneva: World Health Organization.

3. Enas EA, Senthilkumar A, Juturu V, Gupta R. Coronary artery disease in women. Indian heart journal $2001 ; 53(3): 282-92$.

4. Roger VL, Go AS, Lloyd-Jones DM, Benjamin EJ, Berry JD, Borden WB, Bravata DM, et. al American Heart Association Statistics Committee and Stroke Statistics Subcommittee. American Heart Association Statistics Committee and Stroke Statistics SubcommitteeHeart disease and stroke statistics-2012 update: a report from the American Heart Association. Circulation 2012;125(1):e2-e220.

5. Women and research on cardiovascular diseases in Europe: a report from the European Heart Health Strategy (EuroHeart) projectStramba-Badiale M. Eur Heart J 2010;31(14):1677-81d.

6. Castelli WP. Epidemiology of coronary heart disease: the Framingham study. Am J Med 1984;76(2A):4-12.

7. Kannel WB, Wilson PW. Risk factors that attenuate the female coronary disease advantage. Arch Intern Med 1995; 155(1):57-61

8. Mancia G, Fagard R, Narkiewicz K, Redón J, Zanchetti A, Böhm M, Christiaens T, et. al. 2013 ESH/ESC Guidelines for the management of arterial hypertension: the Task Force for the management of arterial hypertension of the European Society of Hypertension (ESH) and of the European Society of Cardiology (ESC). J Hypertens 2013;31(7):1281-357.
9. Aziz F. Coronary Artery Disease in Women: An Unsolved Dilemma. J Clin Med Res 2014;6(2):86-90.

10. Mikhail GW. Coronary heart disease in women. BMJ $2005 ; 331(7515): 467-68$.

11. Pilote L, Dasgupta K, Guru V, Humphries KH, Mc Grath J, Norris C, Rabi D, et. al. A comprehensive view of sex-specific issues related to cardiovascular disease. CMAJ 2007; 176(6):S1-44.

12. Leinwand LA. Sex is a potent modifier of the cardiovascular system. J Clin Invest 2003;112(3):302-307.

13. Kamath SK, Hussain EA, Amin D, Mortillaro E, West B, Peterson CT et al. Cardiovascular disease risk factors in 2 distinct ethnic groups: Indian and Pakistani compared with American premenopausal women. Am J Clin Nutr 1999;69(4):621-31.

14. Manson JE, Colditz GA, Stampfer MJ, Willett WC, Rosner $B$, Monson RR et al. A prospective study of obesity and risk of coronary heart disease in women. $N$ Engl J Med $1990 ; 322(13): 882-89$.

15. Blomkalns AL, Chen AY, Hochman JS, Peterson ED, Trynosky K, Diercks DB et al. Gender disparities in the diagnosis and treatment of non-ST-segment elevation acute coronary syndromes: large scale observations from the CRUSADE (Can Rapid Risk Stratification of Unstable Angina Patients Suppress Adverse Outcomes with Early Implementation of the American College of Cardiology/American Heart Association Guidelines) National Quality Improvement Initiative. J Am Coll Cardiol 2005;45:832-37. doi: 10.1016/j.jacc.2004.11.055.

16. Radovanovic D, Erne $P$, Urban $P$, Bertel O, Rickli $H$, Gaspoz JM et al. Gender differences in management and outcomes in patients with acute coronary syndromes: results on 20,290 patients from the AMIS Plus Registry. Heart 2007;93:1369-75. doi: 10.1136/hrt.2006.106781.

17. Jneid $\mathrm{H}$, Fonarow GC, Cannon $\mathrm{CP}$, Hernandez $\mathrm{AF}$, Palacios IF, Maree AO etal. Sex differences in medical care and early death after acute myocardial infarction. Circulation 2008;118:2803-10. doi: 10.1161/CIRCULATIONAHA.108.789800.

18. Maynard C, Litwin PE, Martin JS, Weaver WD. Gender differences in the treatment and outcome of acute myocardial infarction: results from the Myocardial Infarction Triage and Intervention Registry. Arch Intern Med 1992;152:972-76.

19. Otten AM, Maas AH, Ottervanger JP, Kloosterman A, van 't Hof AW, Dambrink JH et al. Is the difference in outcome between men and women treated by primary percutaneous coronary intervention age dependent? Gender difference in STEMI stratified on age. Eur Heart J Acute Cardiovasc Care 2013;2:334-41. doi: $10.1177 / 2048872612475270$.

20. Mehilli J, Ndrepepa G, Kastrati A, Nekolla SG, Markwardt $\mathrm{C}$, Bollwein $\mathrm{H}$ et al. Gender and myocardial salvage 
after reperfusion treatment in acute myocardial infarction. J Am Coll Cardiol 2005;45:828-31. doi: 10.1016/j.jacc. 2004.11.054.

21. Wijnbergen I, Tijssen J, van 't Veer M, Michels R, Pijls $\mathrm{NH}$. Gender differences in long-term outcome after primary percutaneous intervention for ST-segment elevation myocardial infarction. Catheter Cardiovasc Interv 2013;82:379-84. doi: 10.1002/ccd.24800.

22. Weaver WD, White HD, Wilcox RG, Aylward PE, Morris D, Guerci A et al. Comparisons of characteristics and outcomes among women and men with acute myocardial infarction treated with thrombolytic therapy: GUSTO-I investigators. JAMA 1996;275:777-82.

23. D'Onofrio G, Safdar B, Lichtman JH, Strait KM, Dreyer $\mathrm{RP}$, Geda $\mathrm{M}$ et al. Sex differences in reperfusion in young patients with ST-segment-elevation myocardial infarction: results from the VIRGO study. Circulation 2015;131:1324-32.

24. Bucholz EM, Butala NM, Rathore SS, Dreyer RP, Lansky AJ, Krumholz HM. Sex differences in long-term mortality after myocardial infarction: a systematic review. Circulation 2014;130:757-67. doi: 10.1161/CIRCULATIONAHA.114.009480.

25. Bairey Merz CN, Shaw LJ, Reis SE, Bittner V, Kelsey $\mathrm{SF}$, Olson $\mathrm{M}$ et al. Insights from the NHLBI-sponsored Women's Ischemia Syndrome Evaluation (WISE) Study, part II: gender differences in presentation, diagnosis, and outcome with regard to gender-based pathophysiology of atherosclerosis and macrovascular and microvascular coronary disease. J Am Coll Cardiol 2006;47(suppl):S21-S29. doi: 10.1016/j.jacc.2004.12.084.

26. Mozaffarian D, Benjamin EJ, Go AS, Arnett DK, Blaha MJ, Cushman et al. Heart disease and stroke statistics-2015 update: a report from the American Heart Association [published correction appears in Circulation. 2015;131:e535]. Circulation 2015;131:e29-e322. doi:10.1161/CIR.0000000000000152.

27. Towfighi A, Zheng L, Ovbiagele B. Sex-specific trends in midlife coronary heart disease risk and prevalence. Arch Intern Med 2009;169:1762-6

28. Christine H, Steve F, Anthony O. Hughes. Coronary heart disease and physical activity in South Asian women: Local context and challenges. Health Education Journal 1995;54(4):431-43.
29. El-Menyar, E. Ahmed, H. Albinali, H. Al-Thani, A. Gehani, R. Singh, et al.Mortality trends in women and men presenting with acute coronary syndrome: insights from a 20-year registry, PLoS One 2013;8(7):e70066.

30. Memon MA, Samad A. Acute myocardial infarction in women. Pakistan Journal of cardiology 1999;10:95-107.

31. Hu FB, Stampfer MJ, Rimm EB, et al. Frequent nut consumption and risk of coronary heart disease in women: prospective cohort study. BMJ 1998;317:1341.

32. Demissie S, Cupples LA, Shearman AM, Gruenthal KM, Peter I, Schmid $\mathrm{CH}_{\text {, et }}$ al. Estrogen receptor-alpha variants are associated with lipoprotein size distribution and particle levels in women: the Framingham Heart Study. Atherosclerosis 2006;185(1):210-18.

33. Burt VL, Whelton $P$, Roccella EJ, Brown C, Cutler JA, Higgins $M$, et al. Prevalence of hypertension in the US adult population results from the Third National Health and Nutrition Examination Survey, 1988-1991. Hypertension 1995;25(3):305-13. 